\title{
PENGEMBANGAN DESAIN RUMAH TUMBUH STUDI KASUS PERUMNAS WONOREJO KARANGANYAR
}

\author{
Silfia Mona Aryani, Iik Endang Siti Wahyuningsih, \\ Mulyadi, Andi Setiawan dan Soepono Sasongko* \\ Program Studi S1 Desain Interior Universitas Negeri Sebelas Maret Surakarta
}

\begin{abstract}
This article explains the result of a community service program entitiled assistance on Rumah Inti Tumbuh (RIT) Design Transformation of Wonorejo National Housing Karanganyar. The program was conducted in two steps. The first one was a counseling session for explaining the RIT concept and how the right development is in order to meet the criterion of the healthy and comfort house. This session is purposed for encouraging the owner of how important of right house development without reducingits quality. The second step was the assistance process in developing the RIT. This process considers the previous research conclusion in the transformation preference that are room programming addition, room replacement and room widening. This program focused on the undeveloped units that are planned to be transformed. The assistance will recommend the design that might meet the every family need without compromising the health and comfort aspect. In the end, this community service program is hoped to reduce the bad impact of the development as it is provided by the guidance from the competent experts.
\end{abstract}

Keywords:design transformation, assistance, community service, national housing

\section{PENDAHULUAN}

Rumah inti tumbuh adalah rumah yang dibangun dengan biaya sesuai standar kebutuhan minimal rumah atau cikal bakal RSS. Konsepnya merupakan embrio RSS. Pembangunan bisa dilakukan secara bertahap untuk mencapai standar RSS dan ukuran pembagian ruang berdasarkan pada ukuran standar dan modul internasional untuk rentang gerak/ kegiatan manusia. Rumah tumbuh merupakan sebuah gagasan perencanaan rumah yang dapat dibangun bertahap dengan memperhitungkan jika keluarga muda yang menempati rumah tersebut kelak memiliki anak, taraf ekonomi meningkat, yang secara bertahap berkeinginan untuk mengembangkan ruangan atau merenovasi rumah mereka. RSS dibangun dengan bahan bangunan dan konstruksi yang sederhana, memenuhi standar kebutuhan minimal dari aspek kesehatan, kenyamanan dan keamanan serta mempertimbangkan dan memanfaatkan potensi lokal. Kriterianya antara lain memiliki luas tanah 60-90 $\mathrm{m}^{2}$ dengan luas banguan 21-36 $\mathrm{m} 2$. 

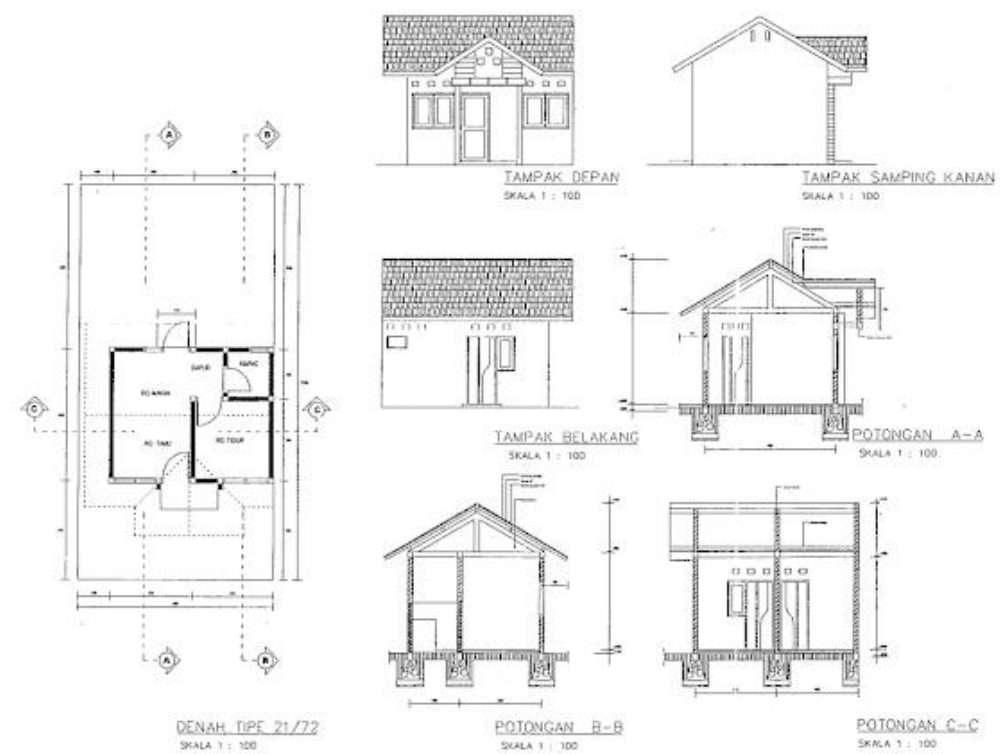

Gambar 1 Rumah pada Perumnas Wonorejo Type 21/72. (Saputra, 2004)

Rumah Perumnas termasuk sebagai rumah inti tumbuh yang pada awal penghunian sudah memenuhi standar kebutuhan minimal rumah atau cikal bakal RSS. Desain rumah inti tumbuh inilah yang menjadi fokus dalam kegiatan pengabdian pada masyarakat ini. Berdasarkan penelitian mengenai transformasi desain rumah yang sudah dilakukan (Aryani, Mulyadi \& Wahyuningsih, 2014), pengabdian berupa pendampingan ini akan merekomendasikan desain pengembangan rumah inti rumah tumbuh. Pendampingan pengembangan desain ini diharapkan mengurangi dampaknegatif perubahan desain yang dilakukan dan tetap mempertahankan kualitas dalam hal kenyamanan dan kesehatan.
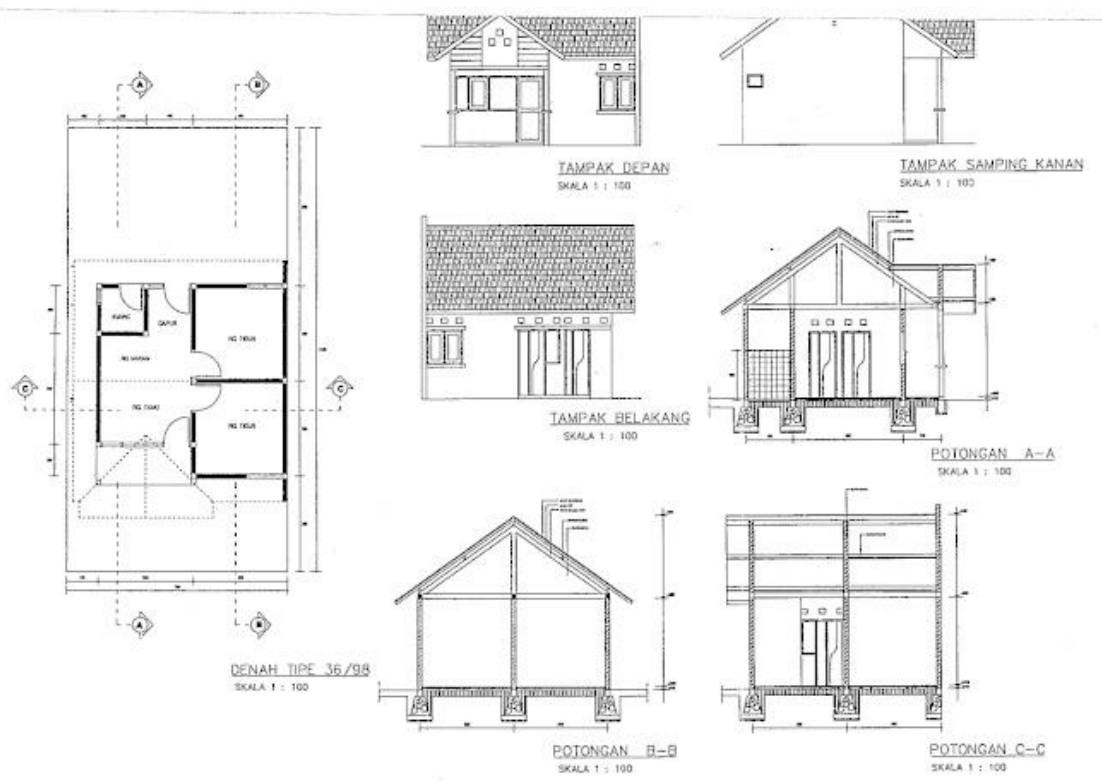

Gambar 2 Rumah pada Perumnas Wonorejo Type 36/98. (Saputra, 2004)

Perumnas Wonorejo yang terpilih sebagai sasaran kegiatan pendampingan dalam pengabdian pada masyarakat ini secara administratif masuk wilayah Kelurahan Wonorejo, Kecamatan Gondangrejo, Kabupaten Dati II Karanganyar. Perumahan ini dibangun oleh Perum Perumnas 
Cabang V unit Surakarta. Secara keseluruhan, Perumnas Wonorejo menempati lahan seluas 27,5 Ha dan dibangun dalam 2 tahap; tahun 1997 - 2002 dan tahun 2003 - 2008. Unit yang ditawarkan terdiri dari 3 jenis type rumah yaitu type 21/72, type 36/98 dan type 45/135 yang semuanya dirancang secara kopel.

Saat ini, sebagian unit di perumahan tersebut sudah mengalami pengembangan yang kemungkinan tidak disertai pengarahan dari pihak yang berkompeten di bidang desain. Oleh karena itu, tim pengabdi bermaksud untuk mengurangi dampak negatif yang mungkin terjadi dengan melakukan kegiatan pendampingan pengembangan desain rumah inti tumbuh pada unit-unit yang belum mengalami perubahan.

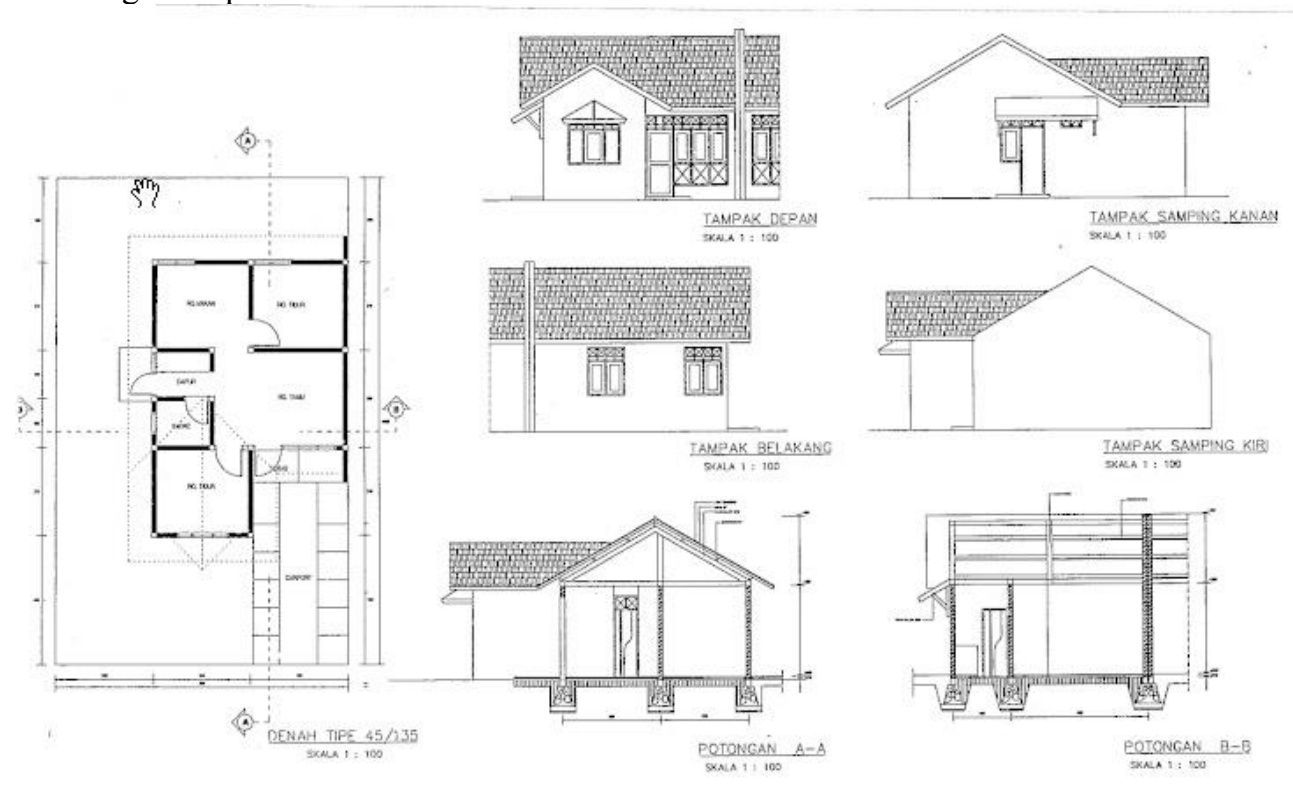

Gambar 3 Rumah Type 45/135 Perumnas Wonorejo. (Saputra, 2004)

\section{PERUMUSAN MASALAH DAN TUJUAN KEGIATAN PENDAMPINGAN}

Rumah Perumnas menarik untuk didampingi pengembangan dan perubahan desainnya. Hal ini karena rumah Perumnas mewakili produk massal hasil generalisasi industri properti yang pada saat pembangunannya masih berorientasi pada ketersediaan produk dalam waktu singkat. Produk massal dinilai mengarah kepada fenomena "housing stress" yaitu suatu kondisi dimana sebuah rumah sudah tidak dapat lagi melayani kebutuhan penghuninya secara fleksibel. Kondisi ini memicu improvisasi, perubahan bentuk bangunan dan perubahan bangunan berkelanjutan. Umumnya penambahan dikarenakan penambahan anggota keluarga maupun kebutuhan ruang lainnya. Oleh karena itu, permasalahan dalam pengabdian pada masyarakat ini dapat dirumuskan sebagai berikut:

1. Bagaimanakah menumbuhkan kesadaran para pemilik unit rumah inti tumbuh terhadap kelayakan huniannya dalam hal kenyamanan dan kesehatan?

2. Bagaimanakah pengembangan desain dari rumah inti tumbuh di Perumnas Wonorejo yang dapat memenuhi kebutuhan di masa datang tanpa harus mengorbankan kualitas rumah dalam hal kenyamanan dan kesehatan? 
Tujuan utama pengabdian pada masyarakat ini adalah untuk melakukan pendampingan pada pemilik unit rumah pada Perumnas Wonorejo dalam mengembangkan desain rumah tumbuh yang dimilikinya. Dengan adanya proses pendampingan dalam pengembangan desain, diharapkan transformasi desain yang dilakukan dapat memenuhi kebutuhan spasial penghuni unit dengan tetap memenuhi standar kenyamanan dan kesehatan. Untuk mencapai tujuan utama tersebut, pengabdian pada masyarakat ini dibagi menjadi 2 tahap pelaksanaan dengan masing-masing bertujuan khusus sebagai berikut:

1. Tujuan khusus pengabdian pada masyarakat tahap pertama adalah untuk mensosialisasikan karakter rumah sehat serta kaitannya dengan konsep rumah inti tumbuh dan pengembangannya.

2. Tujuan khusus pengabdian pada masyarakat tahap kedua adalah untuk mendampingi pemilik unit Perumnas Wonorejo dalam mengembangkan desain awalnya untuk disesuaikan dengan kebutuhannya di masa mendatang.

\section{KAJIAN FENOMENA TRANSFORMASI DESAIN}

Transformasi desain rumah tinggal sudah banyak dibahas dalam artikel ilmiah (Handoko, 1999; Manalang, Munemoto, Yoshida and Espina, 2002; Natakun \& O’Brien, 2009; Nurasrizal, 2010; Sjaifoel, 2008; Sugini, 1999; dan Sueca, 2004). Menurut Tipple (1999), fenomena pengembangan rumah yang dibangun pemerintah umum terjadi di hampir semua negara berkembang. Dampak negatif dari transformasi rumah yang perlu menjadi perhatian dikemukakan oleh Kellet (1993) dan Tipple (1992) dalam Sueca (2004), antara lain penambahan beban utilitas, masalah kurangnya pencahayaan dan penghawaan serta penggunaan sumber daya alam yang tidak efisien. Dari beberapa dampak negatif yang disebutkan ternyata belum pernah ada yang membahasmengenai bagaimana penyelesaian dari permasalahan yang ditimbulkan oleh pengembangan desain sebagai kelanjutan dari maupun penerapan hasil penelitian.

Isu sustainabilitas juga menjadi pertimbangan yang mempengaruhidunia desain. Terkait dengan keberadaan rumah tumbuh yang berkembang seiring proses berarsitektur dari penghuninya, diharapkan penambahan yang dilakukan tidak harus melakukan pengurangan atau perombakan yang berarti. Perubahan maupun perombakan yang besar-besaran akan menghasikan sampah bangunan yang tidak bisa didaurulang. Hal tersebut sebaiknya dihindari karena tidak ramah lingkungan.Oleh karena itu, dalam proses pengembangan RIT menjadi Rs Sehat perlu adanya pendampingan dari pihak profesional dan atau akademisi untuk meminimalisasi dampak negatif pengembangan desain.

\section{METODE PELAKSANAAN}

Pendampingan pengembangan desain rumah inti tumbuh ini difokuskan pada "social situation" (Spradley dalam Sugiyono, 2011: 215) sebagai berikut:

1. Place/Lokasi : Perumnas Wonorejo Surakarta

2. Actors/ Pelaku : Penghuni rumah inti tumbuh pada RW 23 RT 05

3. Activity/Kegiatan: Pendampingan pada proses perubahan desain

Kegiatan ini dilakukan dalam 2 tahap sebagai berikut:

\section{Penyuluhan}

Kegiatan pengabdian pada masyarakat tahap pertama berupa presentasi sudah terlaksana pada Selasa, 11 Agustus 2015 pukul 20.00 - 22.00 di Balai RT 05 RW 23 Wonorejo Indah. Sosialisasi ini bertujuan dalam menumbuhkan kesadaran para pemilik unit rumah akan pentingnya mengembangkan rumah secara tepat agar tidak mengurangi kualitasnya dalam halkenyamanan dan kesehatan. Tumbuhnya kesadaran pemilik rumah inilah yang diperlukan agar kegiatan ini dapat berlangsung dengan sukses.

Materi penyuluhan mencakup konsep rumah tumbuh dan bagaimana pengembangannya yang tepat sehingga tetap memenuhi kriteria sebagai rumah yang sehat dan nyaman. Konsep rumah tumbuh dijelaskan sebagai penguat latarbelakang dilaksanakannya kegiatan pengabdian ini. Materi pengembangan desain yang tepat ditekankan pada 4 aspek yaitu aspek kenyamanan dan kesehatan, aspek keamanan, aspek ekonomi dan aspek keindahan. Ditekankan pula bahwa pengembangan desain rumah hendaknya disesuaikan dengan aktivitas penghuninya. Rumah PERUMNAS sebagai 
poduk massal merupakan hasil generalisasi kegiatan dalam rumah, sehingga dengan personalisasi diharapkan akan semakin menambah kenyamanan penghuniny

Dihadiri oleh 38 warga, peserta terlihat antusias mengenai kegiatan pendampingan. Hal itu nampak pada antusiasme peserta saat sesi tanya jawab. Selain itu, dari 38 hadirin, 28 orang menyatakan kesediaan mereka untuk didampingi dalam perancangan pengembangan rumahnya.

\section{Pendampingan pengembangan desain}

Pendampingan pengembangan yang dilakukan dibatasi sesuai dengan temuan pada penelitian pendahuluan (Aryani, Mulyadi \& Wahyuningsih, 2014) seperti penambahan program ruang, pemindahan ruang dan penambahan luasan ruang. Pengembangan desain terdiri dari pengembangan yang sebagianbesartermasuk type 36/ 98.Pendampingan ini ditujukan pada masyarakat peserta penyuluhan dan yang menyatakan kesediaanya untuk didampingi. Dari 38 kepala keluarga yang hadir pada presentasi penyuluhan tersebut, ada 17 orang yang bersedia didampingi pengembangan rumahnya. Tim P2M telah melaksanakan wawancara untuk mengetahui kebutuhan spasial (need assessment) dan juga mengobservasi kondisi rumah tersebut dilihat dari segi kesehatan, kenyamanan dan keamanannya.

\section{HASIL DAN PEMBAHASAN}

Dari observasi diperoleh beberapa keluhan dari responden terkait dengan kondisi rumah khususnya yang relevan dengan program kegiatan pendampingan ini. $66,7 \%$ penghuni mengeluhkan dinding bermasalah seperti jamur, 83,3\% penghuni merasa kurangnya spatial requirement sehingga berniat menambah ruangan, $16,7 \%$ penghuni merasa kurangnya luasan spasial dan $16,7 \%$ penghuni mengeluhkan panasnya ruangan yang kemungkinan karena kurang tepatnya sistemventilasialami dalam rumah.

Tabel berikut merupakan inventarisasi pengembangan yang sudah dilakukan oleh sasaran kegiatan. Dari data yang ditampilkan, dapat dibaca bahwa sebagian besar sasaran kegiatan telah mengembangkan area belakang rumah. Pengembangan tersebut tidak disertai dengan penyediaan area untuk pengaliran udara buangan. Hal tersebut yang menyebabkan tidak ada aliran angin sehingga ruangan terasa panas. Optimalisasi lahan belakang juga mengarah pada penerusan atap ke belakang dan mengandalkan talang untuk mengalirkan air hujan. Saat curah air hujan tinggi, talang bisa jadi tidak mampu menampung dan mengalirkan dengan kecepatan yang sama sehingga luapannya bisa menyerap ke tembok dan menyebabkan jamur.

Tabel 1 Kecenderungan pengembangan desain rumah PERUMNAS Wonorejo

\begin{tabular}{|l|l|l|}
\hline \multicolumn{1}{|c|}{ Kegiatan Pengembangan } & \multicolumn{1}{|c|}{$\begin{array}{c}\text { Jumlah Kejadian } \\
\text { (dari 16) }\end{array}$} & \multicolumn{1}{c|}{$\begin{array}{c}\text { Tingkat Prioritas } \\
\text { (Skala 1-4) }\end{array}$} \\
\hline Pengembangan lahan belakang & 15 & 3,56 \\
\hline Pengembangan lahan depan & 5 & 1,13 \\
\hline Pengembangan lahan samping & 14 & 3,38 \\
\hline Pengembangan veritkal & 5 & 0,94 \\
\hline Penggantian material & N/A & N/A \\
\hline Pengembangan dengan merubah desain & 5 & 0,31 \\
\hline
\end{tabular}


Berikut adalah rencana perubahan dari desain yang sudah ada yang akan dilakukan oleh

Tabel 2 Rencana perubahan pada program ruang yang ada.

\begin{tabular}{|l|c|c|}
\hline \multicolumn{1}{|c|}{ Rencana Pengembangan Rumah } & $\begin{array}{c}\text { Jumlah Kejadian } \\
\text { (dari 16) }\end{array}$ & $\begin{array}{c}\text { Tingkat Prioritas } \\
\text { (Skala 1-4) }\end{array}$ \\
\hline Merubah dapur & 2 & 0,38 \\
\hline Merubah kamar tidur & 10 & 1,81 \\
\hline Merubah kamar mandi & 9 & 1,31 \\
\hline Merubah ruang tamu & 4 & 0,75 \\
\hline Merubah ruang makan & 0 & 0 \\
\hline Merubah ruang jemuran & 0 & 0 \\
\hline Merubah teras & 1 & 0,25 \\
\hline Menambahkan area komersial & 1 & 0,25 \\
\hline Menambahkan garasi/ carport & 0 & 0 \\
\hline Menambahkan gudan/ ruang serba guna & 0 & 0 \\
\hline Merubah ruang keluarga & 2 & 0,31 \\
\hline Menambahkan musholla & 1 & 0,25 \\
\hline
\end{tabular}

Dari tabel tersebut, dapat dinilai adanya ruangan-ruangan yang belum sesuai dengan kebutuhan spasial penghuninya. Dalam rangka pemenuhan kegiatan tersebut, maka perlu adanya pendampingan agar perubahan yang ada tidak justru menimbulkan masalah di kemudian hari. Sebagai contoh, berikut adalah desain yang diajukan sebagai hasil luaran kegiatan pendampingan.

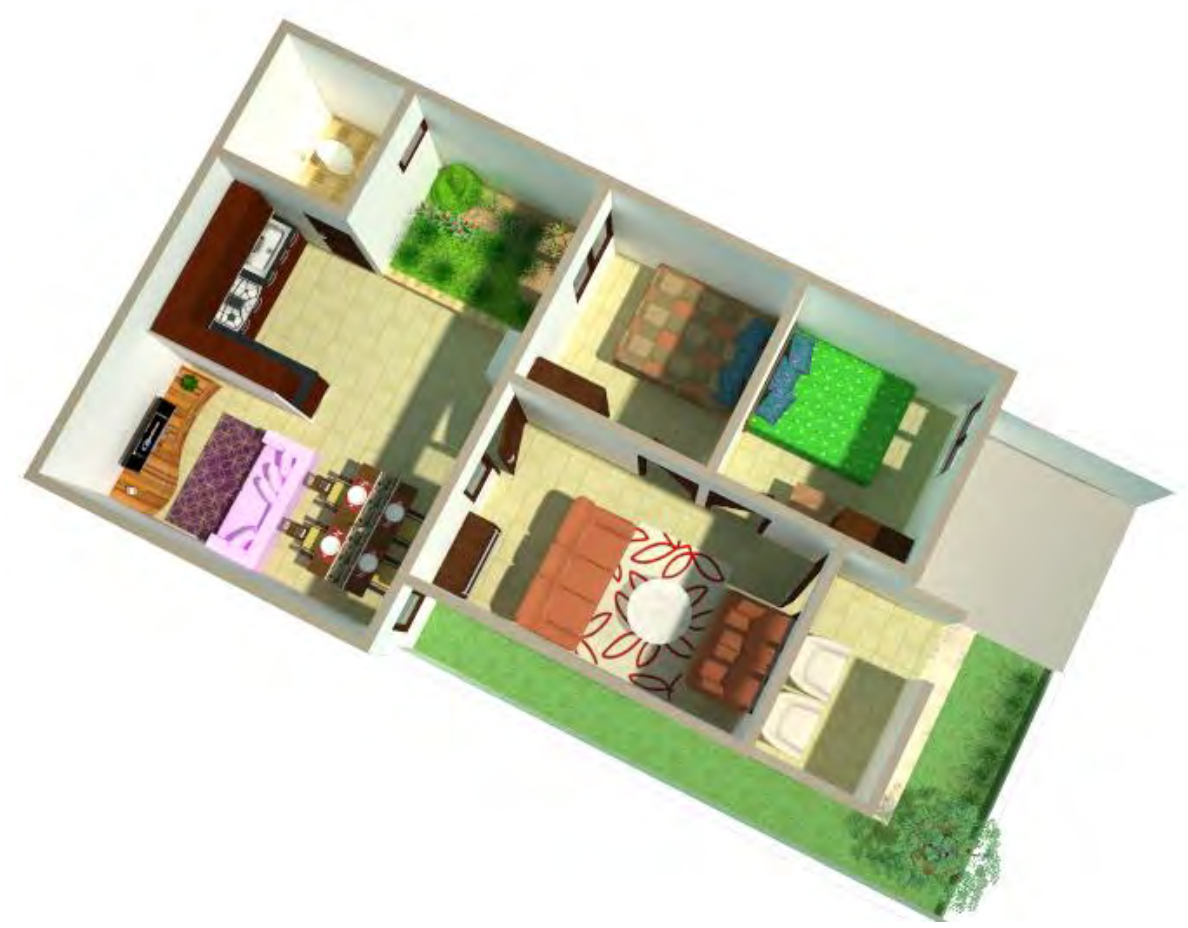

Gambar 4 Contoh rekomendasi desain. 


\section{KESIMPULAN}

Kegiatan ini berdasar pada penelitian terdahulu yang menunjukkan adanya perubahan desain setelah 20 tahun penghunian. Pada kegiatan pengabdian pada masyarakat ini, ditemukan fakta bahwa pemilik unit rumah sudah melakukan perubahan bahkan pada periode kurang dari 5 tahun penghunian. Perubahan yang dilakukan tanpa didampingi oleh tenaga ahli yang kompeten di bidangnya. Beberapa keluhan yang dirasa pada akhirnya mengurangi kualitas rumah yang sudah dikembangkan. Oleh karena itu dengan adanya kegiatan pendampingan ini, hasilnya diharapkan mengurangi dampak negatif dari pengembangan yang akan dilakukan di kemudian hari.

\section{DAFTAR PUSTAKA}

Aryani, S.M., Mulyadi, Wahyuningsih, I.E.S., 2014, StudiPerubahan Spasial Rumah Perumnas; Eksplorasi Desain Inti Rumah Tumbuh, LaporanPenelitianHibahUnggulanFakultas: UniversitasSebelasMaret, Surakarta

Bahan Ajar Perumahan dan Permukiman; Universitas Sumatra Utara: Medan $<$ usupress.usu.ac.id/files/PERUMAHANDANPERMUKIMAN_Normal_bab 1.pdf> diunduh pada 22 Januari 2012

Handoko, B., 1999, Pola Perubahan Rumah Sederhana sebagai Indikasi Pola Perilaku Adaptasi Penghuni; Kasus Studi pada Kompleks Perumahan Sederhana Griya Praja Mukti Kabupaten Dati II Kendal Jawa Tengah, Tesis Program Magister Arsitektur Institut Teknologi Bandung

Manalang, R.T., Munemoto,J., Yoshida,T. \& Espina, C., 2002, ‘A Study on Residents' Self-built Improvement at MRB Dwelling Units in Metro Manila': Journal of Asian Architecture and Building Engineering vol. 1 no. 2 : $177-184$

Natakun,B \& O'Brien,D., 2009, Extending the House / Extending the Dream: Modificationsto Governmentbuilt Housing in Bangkok Metropolitan Region': Journal of Architectural/Planning Research and Studies Volume 6 Issue 3:47-64

Nurasrizal, 2010, Pertumbuhan Rumah Inti Perumahan Layak Huni bagi Keluarga Miskin di Dusun Kayu Gadang Kota Sawahlunto, Tesis Magister Teknik Pembangunan Wilayah dan Kota, Universitas Diponegoro Semarang

Saputra, H.O., 2004, Pengaruh Orientasi Bangunan terhadap Penurunan Panas pada Rumah Tinggal di Perumahan Wonorejo Surakarta, Tesis Magister Teknik Arsitektur, Universitas Diponegoro Semarang

Sasongko, S., Aryani, S.M., Wahyuningsih, I.E.S., Mulyadi \& Setiawan, A., 2015, Pendampingan Pengembangan Desain Rumah Inti Tumbuh; Studi Kasus Perumnas Wonorejo Karanganyar, Laporan Pengabdian pada Masyarakat: UniversitasSebelasMaret, Surakarta

Sjaifoel, E., 2008, Kajian Perubahan Fisik Rumah Tinggal pada Permukiman Perumnas Martubung Medan, Tesis Sekolah Pascasarjana Universitas Sumatera Utara Medan

Sueca, N.P., 2004, 'Transformasi Rumah: Prospeknya untuk Memperbaiki Keadaan Rumah di Indonesia (Suatu Studi Pendahuluan': Jurnal Permukiman Natah Vol. 2 No. 1: 10-16, Universitas Udayana: Denpasar

Sugini, 1999, Tipomorfologi Perubahan Rumah pada Perumahan Minomartani Yogyakarta dalam Jurnal Logika, Volume 3 Nomor 4

Tipple, A.G., 1992, Self HelpTransformation of Low-Cost Housing: With Special Referance to Infrastrusture Issues: diunduh pada 28 Juli $2012<\mathrm{http}$ ://research.ncl.ac.uk/forum/vli1/tipple.pdf>

Tipple, A.G., 1999, ‘Transforming Government-Builr Housing: Lesson from Developing Countries': Journal of Urban Technology Volume 6 Number 2: 17-35

Tjahyono, Y.P.S., 2004, Perumahan bagi Masyarakat Berpenghasilan Menengah ke Bawah di Perkotaan (Sumbang Saran bagi Kemajuan Perum Perumnas pada Ultah ke-29), Dimensi Teknik Arsitektur, Universitas Petra: Surabaya 